\title{
Duas novas espécies de Alphomelon Mason, 1981 (Hymenoptera, Braconidae, Microgastrinae) do Brasil
}

\author{
Paloma Helena Fernandez Shimabukuro ${ }^{1}$ \\ Angélica Maria Penteado-Dias ${ }^{2}$
}

\begin{abstract}
Aвstract. Two new species of Alphomelon Mason, 1981 (Hymenoptera, Braconidae, Microgastrinae) from Brazil. Alphomelon brasiliensis sp. nov. (from São Paulo) and A. rugosus sp. nov. (from Rio Grande do Sul) are described and a key to species is presented.
\end{abstract}

Keywords. Alphomelon; Braconidae; Brazil; Microgastrinae; new species.

\section{INTRODUÇÃO}

O gênero Alphomelon Mason, 1981 é constituído por endoparasitóides coinobiontes, de hábito solitário ou gregário, de larvas de Hesperiidae (Lepidoptera) e são muito importantes para a regulação das populações deste grupo (MASON 1981). Além dos Alphomelon, os Hesperiidae também são parasitados por outros grupos de Hymenoptera: Eulophidae (SCHAUFF 2000), Agathidinae (JANZEN et al. 1998) e alguns dípteros da família Tachinidae (TEMERAK et al. 1984).

Alphomelon caracteriza-se por ter tamanho grande $(3-6 \mathrm{~mm})$ dentro dos Microgastrinae, uma mácula branca presente na gena e bainhas do ovipositor de tamanho médio, com pêlos ao longo de todo comprimento. O propódeo tem escultura áspera e uma aréola completa. A margem do lobo vanal da asa posterior não possui pêlos e é usualmente côncava. As garras tarsais podem ter de 1 a 4 espinhos. O primeiro tergito é um pouco mais longo que largo, de lados subparalelos, com uma carena mediana divergente em forma de "Y"; o segundo tergito é retangular e 3-4 vezes mais largo que longo.

São três as espécies já descritas: Alphomelon talidicida (Wilkinson, 1931), não encontrada no Brasil, mas com ocorrência na Guiana, A. nigriceps (Ashmead, 1900) com distribuição ampla nos Estados do Amazonas, Pernambuco, Mato Grosso e São Paulo, e A. disputabilis (Ashmead, 1900) que ocorre apenas no Estado de São Paulo. Estima-se, entretanto, que seja um gênero rico em espécies, a maioria neotropical (MASON 1981).
A terminologia empregada para a venação das asas segue MASON (1981) e para a escultura, EADY (1968).

O material foi coletado através de armadilhas do tipo Malaise (Townes 1972) e pelo método de varredura da vegetação em ambientes de cerrado e de matas mesófila e ciliar. A. brasiliensis sp. nov. foi coletada nos meses de janeiro a maio, em julho e de outubro a dezembro, de 1998 a 2000; A. rugosus sp. nov. foi coletada nos meses de março, julho e dezembro, nos anos de 1982, 1986, 1987, 1999 e 2000.

O material examinado encontra-se depositado na coleção do Departamento de Ecologia e Biologia Evolutiva, Universidade Federal de São Carlos, São Carlos (DCBU).

Chave para espécies de Alphomelon

1. Primeiros esternitos abdominais amarelos …………....... 2

Primeiros esternitos abdominais castanhos 3

2(1). Cabeça e mesossoma pretos; dois espinhos basais na garra tarsal (Fig. 1) A. brasiliensis sp. nov.

Cabeça preta, mesossoma e metassoma castanhos; um espinho basal na garra tarsal

A. nigriceps (Ashmead, 1900)

3(2). Lúnula semicircular, asa levemente esfumaçada no ápice A. talidicida (Wilkinson, 1931)

Lúnula triangular, asas hialinas 4

1. Programa de Pós-graduação em Ecologia e Recursos Naturais, Universidade Federal de São Carlos. Caixa Postal 676, 13565-905 São CarlosSP, Brasil. Endereço eletrônico:phfs@yahoo.com. Bolsista CAPES.

2. Departamento de Ecologia e Biologia Evolutiva, Universidade Federal de São Carlos. Caixa Postal 676, 13565-905 São Carlos-SP, Brasil. Endereço eletrônico:angelica@power.ufscar.br. Bolsista CNPq. 


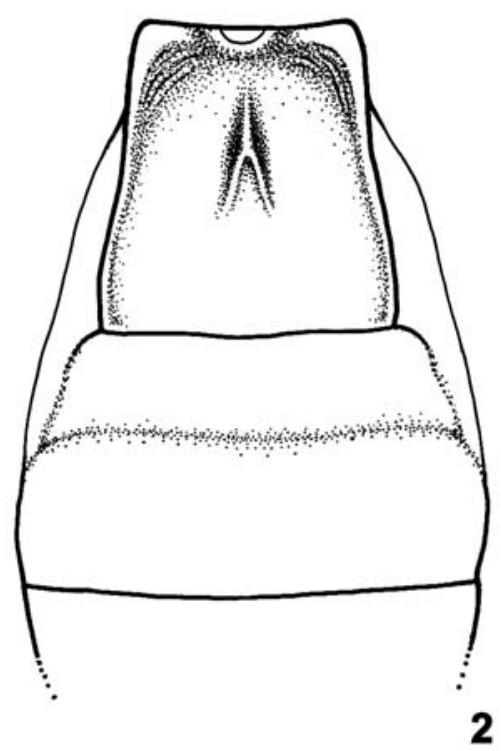

2

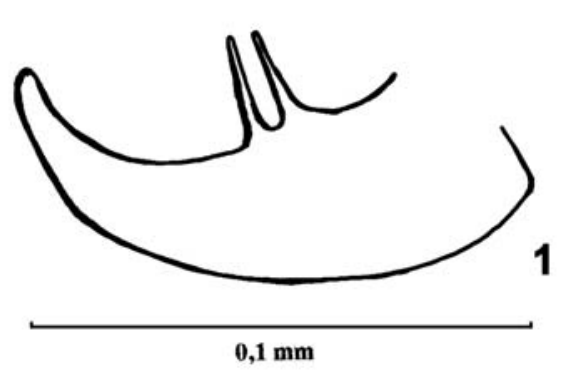

1

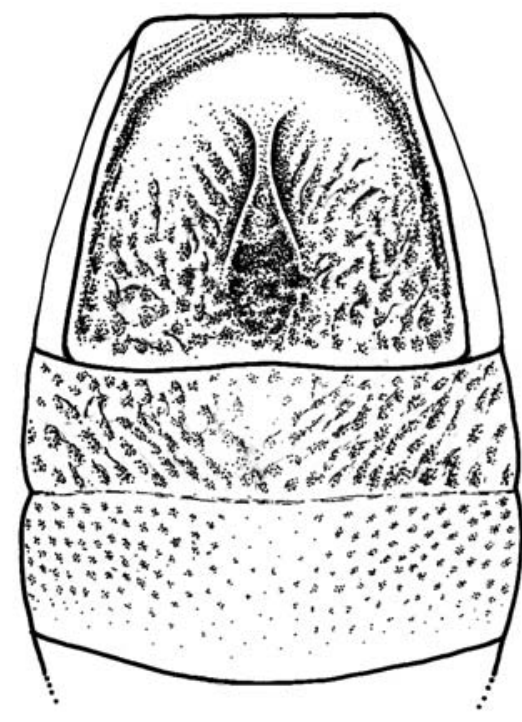

3

Figs. 1-3. 1,2, Alphomelon brasiliensis sp. nov., holótipo fêmea: 1, garras tarsais; 2, tergitos 1-3. 3, Alphomelon rugosus sp. nov., holótipo fêmea, tergitos $1-3$.

4(3). Metassoma esculturado (Fig. 3); dois espinhos basais na garra tarsal; estigma castanho .....

A. rugosus sp. nov.

Metassoma liso; um espinho basal na garra tarsal; estigma com margem castanha e porção interna amarela . A. disputabilis (Ashmead, 1900)

\section{Alphomelon brasiliensis sp. nov.} (Figs. 1, 2)

Holótipo fêmea. Comprimento do corpo 4,4 mm.

Coloração. Cabeça e mesossoma pretos; metassoma castanho, com os primeiros esternitos amarelos.

Cabeça. Finamente pontuada, triangular e alongada; clípeo e labro castanhos, palpos maxilares com o primeiro artículo castanho e o restante amarelo, os labiais com os dois primeiros artículos castanhos, os demais amarelos; mácula presente na gena se estende desde a margem do clípeo até o occipício; escapo e pedicelo pretos, flagelômeros castanho-escuros; ocelos formam um triângulo pouco saliente.

Mesossoma. Mesoscuto e escutelo lisos, brilhantes; lúnula triangular, polida na porção mediana; mesopleura lisa; propódeo com aréola hexagonal, com rugosidades na região anterior e coriáceo na região posterior; tégula amarela; asa com nervuras castanhas, estigma castanho. Pernas anteriores com coxa e trocânter castanhos, o restante alaranjado; pernas posterior e média com coxas pretas, trocânteres castanhos, o restante alaranjado; ápice dos fêmures, tíbias e tarsômeros posteriores castanho-escuros, o restante alaranjado. Garra tarsal com 2 espinhos (Fig.1).

Metassoma. Primeiro tergito castanho-escuro, com área central alaranjada, um pouco estreitado anteriormente, liso e brilhante; carena em "Y" no primeiro tergito pouco divergente e bem definido, com algumas estriações ao longo desta carena; segundo tergito castanho, transversal, de forma trapezoidal; terceiro tergito duas vezes mais longo que o segundo (Fig. 2); quarto a sétimo tergitos lisos, brilhantes, com fileiras transversais de pêlos longos; bainha do ovipositor castanha.

Material-tipo. Holótipo fêmea. BRASIL. São Paulo, São Carlos, Campus da Universidade Federal de São Carlos, em área de cerrado, 28.III.2000, Luís A. Joaquim, col., armadilha Malaise (DCBU). Parátipos. BRASIL. Minas Gerais: Sete Lagoas, 19.IV-02.V.2000 (1 fêmea), 26.VI10.VII.2000 (1 fêmea), Cerrado, W. Matrangolo, col. São Paulo: São Carlos, Campus da Universidade Federal de São Carlos, 14.IV.1998 (1 fêmea), 30.IV.1998 (1 fêmea), 25.V.1998 (1 fêmea), Luís A. Joaquim, col., Cerrado, armadilha Malaise; Fazenda Canchim (EMBRAPA, CPPSE), 28.I-11.II.1998 (2 fêmeas), 18.III.1998 (1 fêmea), 26.XII.199709.I.1998 (1 fêmea), Luís A. Joaquim, col., Mata mesófila semidecídua, armadilha Malaise; Matão, Fazenda Cambuhy, 03.XI.2000 (1 fêmea), Luís A. Joaquim, col., Mata mesófila semidecídua, varredura da vegetação; Descalvado, Fazenda Santa Marina, 25.VII.1999 (1 fêmea), K.R.N. Cirelli, col. Rio Grande do Sul: Marcelino Ramos, 22.XII.2000 (1 fêmea), 23.XI.1999 (1 fêmea), R.M. Restello, col., Mata mesófila, armadilha Malaise (DCBU).

Variação. A coloração de algumas áreas dos tergitos varia de preto a castanho-claro.

Considerações taxonômicas. Alphomelon brasiliensis $\mathbf{s p .}$ nov. difere de $A$. talidicida (Wilkinson, 1931) pela lúnula triangular e asas hialinas; em $A$. talidicida a lúnula é semicircular e as asas têm a extremidade escurecida. Difere de $A$. disputabilis (Ashmead, 1900) por ter estigma uniformemente castanho e primeiros esternitos abdominais amarelos; $A$. disputabilis tem estigma com margem castanha e interior 
amarelo e os primeiros esternitos abdominais castanho-escuros. Difere de A. nigriceps (Ashmead, 1900) pela coloração do corpo; A. brasiliensis sp. nov. tem corpo preto e $A$. nigriceps tem somente a cabeça preta, o restante do corpo é castanho.

Etimologia. O nome da espécie refere-se à sua ocorrência no Brasil.

\section{Alphomelon rugosus sp. nov.}

(Fig. 3)

Holótipo fêmea. Comprimento do corpo 3,9 mm.

Coloração. Cabeça, mesossoma e metassoma pretos.

Cabeça. Finamente pontuada com granulações; clípeo, labro e mandíbulas pretos, palpos maxilares amarelos, os labiais castanhos; mácula presente na gena se estende da margem do clípeo mas não atinge occipício; escapo e pedicelo pretos, flagelômeros castanho-escuros.

Mesossoma. Mesoscuto finamente pontuado com granulações; escutelo liso; lúnula triangular polida na área central; mesopleura rugosa; propódeo rugoso com aréola pentagonal; asa como em $A$. brasiliensis sp. nov., tégula castanha; pernas com coxas pretas, trocânteres e trocantelos castanhos, o restante alaranjado; perna posterior com ápice da tíbia, fêmur e primeiro tarsômero castanhos, demais tarsômeros castanho-claros. Garra tarsal com 2 espinhos.

Metassoma. Preto; primeiro tergito mais largo apicalmente, estriado anteriormente, com fóveas na região posterior, carena em "Y" bem marcada e saliente; segundo tergito preto, estriado e com fóveas posteriores; terceiro tergito com região anterior rugosa, tornando-se lisa em direção ao ápice (Fig. 3); quarto tergito e demais lisos, pretos, com fileiras de pêlos brancos; bainhas do ovipositor castanho-escuras.

Material-tipo. Holótipo fêmea, BRASIL: Rio Grande do Sul, Marcelino Ramos, 22.XII.2000, R.M. Restello, col., Mata mesófila, armadilha Malaise (DCBU). Parátipos. BRASIL. Distrito Federal: Brasília, Reserva Ecológica do IBGE, 23-30.XII.1982, (1 fêmea), Cerrado. São Paulo: Descalvado, Fazenda Ibicatu, 25.VII.1999 (1 fêmea), K.R.N. Cirelli, col., Mata ciliar, armadilha Malaise; Luís Antônio, Reserva Ecológica do Jataí, 07.V.1987, (1 fêmea), Luís A. Joaquim, col., Cerrado; São Carlos, Fazenda Canchim (EMBRAPA, CPPSE), 30.IV.1986 (1 fêmea), Luís A. Joaquim, col., Mata mesófila semidecídua, varredura da vegetação. Rio Grande do Sul: Marcelino Ramos, 15.III.2000 (1 fêmea), R.M. Restello, col., Mata mesófila, armadilha Malaise (DCBU).
Considerações taxonômicas. Alphomelon rugosus sp. nov. difere das demais espécies devido à presença de escultura no metassoma; difere de $A$. talidicida pela lúnula triangular e asas hialinas; em $A$. talidicida a lúnula é semicircular, as asas têm a extremidade escurecida e o metassoma não é rugoso. Difere de A. disputabilis por ter estigma uniformemente castanho e pela escultura dos tergitos; A. disputabilis tem estigma com margem castanha e interior amarelo e metassoma sem escultura. Difere de $A$. nigriceps pelo corpo preto e metassoma rugoso; $A$. nigriceps tem somente a cabeça preta, o restante do corpo é castanho e o metassoma não possui escultura.

Etimologia. O nome da espécie refere-se à escultura do metassoma.

Agradecimentos. À CAPES (Coordenação de Aperfeiçoamento de Pessoal de Nível Superior), CNPq (Conselho Nacional de Desenvolvimento Científico e Tecnológico) e FAPESP (Fundação de Apoio à Pesquisa do Estado de São Paulo) pelo auxílio financeiro; à Gláucia Marconato pela confecção das figuras; ao CPPSE (Centro de Pesquisa em Pecuária do Sudeste, EMBRAPA, São Carlos) por permitir trabalhos em área da Fazenda Canchim.

\section{REFERÊNCIAS}

EADY, R. D. 1968. Some illustrations of microsculpture in the Hymenoptera. Proceedings of the Royal Entomological Society of London, Series A, 43: 66-72.

JanZen, D. H.; M. J. Sharkey \& J. M. Burns. 1998. Parasitization biology of a new species of Braconidae (Hymenoptera) feeding on larvae of Costa Rican dry forest skippers (Lepidoptera: Hesperiidae: Pyrginae). Tropical Lepidoptera 9 (Suppl. 2): 33-41.

Mason, W. R. M. 1981. The polyphyletic nature of Apanteles Foerster (Hymenoptera: Braconidae): a phylogeny and reclassification of Microgastrinae. Memoirs of the Entomological Society of Canada 115: 1-147.

Schauff, M. E. 2000. A new genus and species of Eulophidae (Hymenoptera) from Costa Rica with notes on the genus. Proceedings of the Entomological Society of Washington 102 (2): 403-407.

TemeraK, S. A; D. G. Boucias \& W. H. Whitcomb. 1984. A singly-embedded nuclear polyhedrosis virus and entomophagous insects associated with populations of the bean leafroller Urbanus proteus (Lepidoptera, Hesperiidae). Zeitschrift Fuer Angewandte Entomologie 97(2): 187-191.

Townes, H. 1972. A light-weight Malaise trap. Entomological News 83: $239-247$. 